\title{
Novel Contribution of Long Non-coding RNA MEG3 Genotype to Prediction of Childhood Leukemia Risk
}

\author{
JEN-SHENG PEI ${ }^{1 *}$, WEN-SHIN CHANG ${ }^{2,3^{*}}$, CHAO-CHUN CHEN $^{1 *}$, MEI-CHIN MONG ${ }^{4}$, SHIH-WEI HSU ${ }^{5}$, \\ PEI-CHEN HSU ${ }^{1}$, YUAN-NIAN HSU ${ }^{6}$, YUN-CHI WANG ${ }^{2,3}$, CHIA-WEN TSAI $^{2,3}$ and DA-TIAN BAU ${ }^{2,3,7}$ \\ ${ }^{1}$ Department of Pediatrics, Taoyuan General Hospital, Ministry of Health and Welfare, Taoyuan, Taiwan, R.O.C.; \\ ${ }^{2}$ Graduate Institute of Biomedical Sciences, China Medical University, Taichung, Taiwan, R.O.C.; \\ ${ }^{3}$ Terry Fox Cancer Research Laboratory, Department of Medical Research, \\ China Medical University Hospital, Taichung, Taiwan, R.O.C.; \\ ${ }^{4}$ Department of Food Nutrition and Health Biotechnology, Asia University, Taichung, Taiwan, R.O.C.; \\ ${ }^{5}$ Taichung Armed Forces General Hospital, Taichung, Taiwan, R.O.C.; \\ ${ }^{6}$ Department of Family Medicine, Taoyuan General Hospital, \\ Ministry of Health and Welfare, Taoyuan, Taiwan, R.O.C.; \\ ${ }^{7}$ Department of Bioinformatics and Medical Engineering, Asia University, Taichung, Taiwan, R.O.C.
}

\begin{abstract}
Background/Aim: Acute lymphoblastic leukemia $(A L L)$ is frequent among children. Few studies have researched the relationship between maternally expressed gene 3 (MEG3) and cancer risk. We hypothesized long noncoding RNA MEG3 polymorphisms might influence the risk of childhood ALL. Materials and Methods: In a total of 266 patients with childhood ALL and 266 healthy controls, genotypes of MEG3 rs7158663, rs3087918, rs 11160608 and rs4081134 single nucleotide polymorphisms were investigated for their associations with childhood ALL. Results: MEG3 rs7158663 AG and AA genotypes were significantly associated with ALL [odds ratio=1.61 $(95 \%$ confidence interval=1.12-2.31) and 2.21 (1.16-4.22), respectively]. The $A$ allele also exhibited a statistical association with higher risk of ALL ( $p=0.0015)$. There was no positive association as for rs3087918, rs11160608 or rs4081134. Interestingly, a significant interaction between MEG3 rs 7158663 and age ( $\geq 3.5$ years) and gender (male)
\end{abstract}

This article is freely accessible online.

*These Authors contributed equally to this study.

Correspondence to: Da-Tian Bau and Chia-Wen Tsai, Terry Fox Cancer Research Laboratory, Department of Medical Research, China Medical University Hospital, 2 Yuh-Der Road, Taichung, 404 Taiwan, R.O.C. Tel: +886 422053366 (Ext. 5805), e-mail: datian@mail.cmuh.org.tw (D-TB); artbau2@gmail.com (D-TB)

Key Words: Childhood leukemia, genotype, MEG3, polymorphism, Taiwan. was found. Conclusion: MEG3 rs7158663 AG/AA genotypes were associated with higher susceptibility to childhood ALL. These novel findings should be validated in larger populations and different ethnicities.

Childhood acute lymphoblastic leukemia (ALL) is a malignant disorder commonly found among children and frequently in children less than 15 years of age. The peak ages of early onset are 2-5 years old $(1,2)$, accounting for approximately one-third of childhood tumors (3). The etiology and pathogenesis remain unclear, and it is believed that childhood ALL is the consequence of a combinative influence of genetic variations and lifestyle/environmental factors $(4,5)$. In recent years, there is mounting evidence that single nucleotide polymorphisms (SNPs) may play an important role in determining the risk for childhood ALL (611). However, the role of many genetic factors is unclear, and further exploration of the complex genomic understanding about childhood ALL is urgently needed.

Long non-coding RNAs (lncRNA) are defined as RNAs longer than 200 nucleotides and form a novel group of noncoding RNAs, with microRNA-like features, which are not translated into functional proteins (12). Mounting evidence has shown that lncRNAs play a critical role in controlling a variety of biological processes, including leukemia progression, immune regulation, carcinogenesis, tumor metastasis and drug resistance (13-15). The maternally expressed gene 3 (MEG3) encodes a myelocyte-related lncRNA and is believed to be involved in the process of carcinogenesis and responsiveness to chemotherapy $(16,17)$. MEG3 is considered a tumor suppressor (15). It has been reported to play a role in several 
types of cancer, including bladder (18), gastric (19), and lung (20), as well as hepatocellular carcinoma (21). Accumulating evidence has suggested that genetic variants in the MEG3 gene predispose to cancer. However, the impacts of MEG3 polymorphisms in childhood ALL remain unclear. According to the information above, we were interested in investigating the contribution of MEG3 genotypes to childhood ALL. We also summarize the literature on the associations of $M E G 3$ genotypes with various types of cancer to provide the reader with a better understanding of the contribution of MEG3 genotype to cancer risk.

\section{Materials and Methods}

Recruitment of childhood leukemia cases and healthy controls. Childhood ALL cases were ascertained by pediatric oncologists with pathological confirmation. All the recruited cases completed a questionnaire with help from their parents or guardians, and donated blood samples. Healthy controls without prior history of any tumor were recruited in the same period. Healthy controls were matched to each case by age ( \pm 2 years) and gender. All the participants were Taiwanese. This study was approved by the Institutional Review Board of China Medical University Hospital (DMR103-IRB-153).

Genotyping methodology for MEG3 genotype. Peripheral blood was collected from each participant and the genomic DNA was extracted

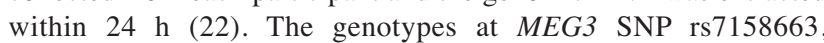
rs3087918, rs11160608 and rs4081134 were determined using a TaqMan assay with an ABI 7500 Real-Time PCR System (Applied Biosystems, Foster City, CA, USA). For quality control, two negative controls (distilled water without DNA sample) were included in each 96-well plate. Furthermore, genotyping of about $3 \%$ of randomly selected samples was repeated in a blind fashion to confirm the genotyping results.

Statistical methodology. The good-of-fit chi-square test was used to tests for deviation from Hardy-Weinberg equilibrium of the selected polymorphic sites. Student's $t$-test was used to check the distributions of ages. Pearson's chi-square methodology was used in checking the distribution pattern of $M E G 3$ genotypes and the interaction of MEG3 genotype with age and gender. The contribution of MEG3 genotypes to childhood ALL were also validated with the corresponding odds ratios (ORs) and 95\% confidence intervals (CIs). Any association with a $p$-value less than 0.05 was considered statistically significant

\section{Results}

Comparison of basic and clinical demographics. The distributions of age of ALL onset, gender and white blood cell counts of childhood ALL cases and matched healthy controls are shown in Table I. In addition, the immunophenotype, risk classification and survival time of the childhood leukemia cases are also shown. There was no difference in distributions of age and gender between the cases and controls $(p>0.05)$ since the two groups were matched for these indices (Table I). The mean white blood
Table I. Distribution of some basic and clinical demographics of the 266 patients with childhood acute lymphoblastic leukemia and the 266 matched controls.

\begin{tabular}{|c|c|c|c|}
\hline Characteristic & $\begin{array}{l}\text { Controls } \\
(\mathrm{n}=266)\end{array}$ & $\begin{array}{l}\text { Cases } \\
(\mathrm{n}=266)\end{array}$ & $p$-Value \\
\hline \multicolumn{4}{|c|}{ Age at onset age, years } \\
\hline Mean \pm SD & $8.3 \pm 4.8$ & $7.0 \pm 4.4$ & $0.6483^{\mathrm{a}}$ \\
\hline \multicolumn{4}{|l|}{ Gender, n (\%) } \\
\hline Male & $148(55.6 \%)$ & $148(55.6 \%)$ & \\
\hline Female & $118(44.4 \%)$ & $118(44.4 \%)$ & $>0.99^{b}$ \\
\hline \multicolumn{4}{|c|}{$\begin{array}{l}\text { White blood cell count } \\
\left(\times 10^{9} / 1\right)\end{array}$} \\
\hline Mean \pm SD & $7.5 \pm 2.0$ & $54.3 \pm 75.9$ & $<0.0001$ \\
\hline \multicolumn{4}{|c|}{ Immunophenotype, n (\%) } \\
\hline B Subtype & & $227(85.3 \%)$ & \\
\hline T Subtype & & $39(14.7 \%)$ & \\
\hline \multicolumn{4}{|c|}{ Risk classification, n (\%) } \\
\hline Standard risk & & $130(48.9 \%)$ & \\
\hline High risk & & $67(25.2 \%)$ & \\
\hline Very high risk & & $69(25.9 \%)$ & \\
\hline \multicolumn{4}{|l|}{ Survival, years } \\
\hline$<5$ Years & & $69(25.9 \%)$ & \\
\hline$\geq 5$ Years & & $197(74.1 \%)$ & \\
\hline
\end{tabular}

SD: Standard deviation. aBased on Student's $t$-test; based on chi-square test without Yates' correction. Statistically significant $p$-values are shown in bold.

cell count of childhood ALL cases was significantly higher than those of healthy controls $(p<0.0001)$. Among the patients, $48.9 \%$ (130 in number) were at standard risk, $25.2 \%$ (67 in number) were at high risk, and $25.9 \%$ (69 in number) were at very high risk. Lastly, $25.9 \%$ of the patients survived less than 5 years (Table I).

Significant association between MEG3 rs7158663 genotypes and childhood ALL. The genotypic distributions of MEG3 rs7158663 among the controls and the childhood ALL patients are presented and analyzed in Table II. Firstly, the genotypic frequencies of MEG3 rs7158663 among the control individuals were in Hardy-Weinberg equilibrium ( $p=0.7108)$. Secondly, the genotypes of MEG3 rs7158663 were differently distributed between the childhood ALL and healthy control groups ( $p$ for trend=0.0064) (Table II). Carrying MEG3 rs7158663 heterozygous AG or homozygous AA genotype was associated with an increased childhood ALL risk, compared with the wild-type GG genotype $(\mathrm{OR}=1.61$ and $2.21,95 \% \mathrm{CI}=1.12-2.31$ and 1.16-4.22; $p=0.0097$ and 0.0142 , respectively). Thirdly, in the recessive model, compared with those carrying GG and AG genotypes, risk of ALL for homozygous variant AA genotype carriers at MEG3 rs7158663 did not reach a significant level $(\mathrm{OR}=1.79$, 95\% CI=0.96-3.35; $p=0.0641)$. Fourthly, in the dominant model, there was an increased risk of childhood ALL for 
Table II. Maternally expressed gene 3 (MEG3) rs7158663 genotypes among the 266 patients with childhood acute lymphoblastic leukemia and 266 healthy controls.

\begin{tabular}{|c|c|c|c|c|c|}
\hline & & Controls, n (\%) & Patients, n (\%) & OR $(95 \% \mathrm{CI})$ & $p$-Value ${ }^{a}$ \\
\hline \multirow[t]{5}{*}{ Genotype } & GG & $153(57.5 \%)$ & $118(44.4 \%)$ & 1.00 (Reference) & \\
\hline & $\mathrm{AG}$ & $96(36.1 \%)$ & $119(44.7 \%)$ & $1.61(1.12-2.31)$ & 0.0097 \\
\hline & AA & $17(6.4 \%)$ & $29(10.9 \%)$ & $2.21(1.16-4.22)$ & 0.0142 \\
\hline & $p_{\text {trend }}$ & & & & 0.0064 \\
\hline & $p_{\mathrm{HWE}}$ & & & & 0.7108 \\
\hline \multirow{4}{*}{ Carrier comparison } & $\mathrm{GG}+\mathrm{AG}$ & $249(93.6 \%)$ & $237(89.1 \%)$ & 1.00 (Reference) & \\
\hline & AA & $17(6.4 \%)$ & $29(10.9 \%)$ & $1.79(0.96-3.35)$ & 0.0641 \\
\hline & GG & $153(57.5 \%)$ & $118(44.4 \%)$ & 1.00 (Reference) & \\
\hline & $\mathrm{AG}+\mathrm{AA}$ & $113(42.5 \%)$ & $148(55.6 \%)$ & $1.70(1.21-2.39)$ & 0.0024 \\
\hline
\end{tabular}

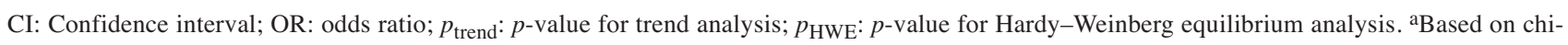
square test without Yates' correction. Statistically significant $p$-values are shown in bold.

Table III. Maternally expressed gene 3 (MEG3) rs3087918 genotypes among the 266 patients with childhood acute lymphoblastic leukemia and 266 healthy controls.

\begin{tabular}{|c|c|c|c|c|c|}
\hline & & Controls, n (\%) & Patients, n (\%) & OR $(95 \% \mathrm{CI})$ & $p$-Value ${ }^{\mathrm{a}}$ \\
\hline \multirow[t]{5}{*}{ Genotype } & TT & $98(36.9 \%)$ & $105(39.5 \%)$ & 1.00 (Reference) & \\
\hline & GT & $128(48.1 \%)$ & $129(48.5 \%)$ & $0.94(0.65-1.36)$ & 0.7445 \\
\hline & GG & $40(15.0 \%)$ & $32(12.0 \%)$ & $0.75(0.44-1.28)$ & 0.2885 \\
\hline & $p_{\text {trend }}$ & & & & 0.5672 \\
\hline & $p_{\mathrm{HWE}}$ & & & & 0.8647 \\
\hline \multirow[t]{4}{*}{ Carrier comparison } & $\mathrm{TT}+\mathrm{GT}$ & $226(85.0 \%)$ & $234(88.0 \%)$ & 1.00 (Reference) & \\
\hline & GG & $40(15.0 \%)$ & $32(12.0 \%)$ & $0.77(0.47-1.27)$ & 0.3106 \\
\hline & $\mathrm{TT}$ & $98(36.9 \%)$ & $105(39.5 \%)$ & 1.00 (Reference) & \\
\hline & $\mathrm{GT}+\mathrm{GG}$ & $168(63.1 \%)$ & $161(60.5 \%)$ & $0.89(0.63-1.27)$ & 0.5321 \\
\hline
\end{tabular}

CI: Confidence interval; OR: odds ratio; ptrend: $p$-value for trend analysis; $p_{\mathrm{HWE}}: p$-value for Hardy-Weinberg equilibrium analysis. ${ }^{\mathrm{a} B a s e d}$ on chi-square test without Yates' correction.

those carrying an A allele at MEG3 rs7158663, compared with those with homozygous GG genotype (OR=1.70, 95\% $\mathrm{CI}=1.21-2.39, p=0.0024)$. These results showed that $\mathrm{AG}$ and AA genotype carriers at MEG3 rs7158663 had a significantly elevated risk for childhood ALL.

Non-significant association for other MEG3 SNPs examined. The genotypic distributions of $M E G$ rs3087918, rs11160608, and rs4081134 are presented and analyzed in Table III, Table IV and Table V, respectively. The genotypic frequencies of MEG3 rs3087918, rs11160608, and rs4081134 among the control individuals all fit the Hardy-Weinberg equilibrium (all $p>0.05$ ). However, none of these SNPs seemed to be significantly associated with ALL in any model analyzed (all $p>0.05$ ).

Allelic frequency distribution analysis supported the findings. To validate the results shown in Table II to Table V, analysis of the allelic frequency distribution for MEG3 rs7158663, rs3087918, rs11160608, and rs4081134 SNPs were conducted, and the results are shown in Table VI. Most importantly, the variant A allele at MEG3 rs7158663 was found in $33.3 \%$ in the childhood ALL group and in $24.4 \%$ in the control group $(\mathrm{OR}=1.54,95 \% \mathrm{CI}=1.18-2.01, p=0.0015$, Table VI). This supports the finding that the A allele was associated with an increased risk of childhood ALL in Taiwanese. For other SNPs, including rs3087918, rs11160608, and rs4081134, none of the variant alleles seemed to be significantly associated with childhood ALL risk.

Interaction of MEG3 rs7158663 genotypes with age and gender. We were interested in examining whether there was any difference of MEG3 rs7158663 genotypes according to age and gender. Table VII shows that among children aged less than 3.5 years, those with MEG3 rs7158663 AG and AA variant genotypes had non-significant odds of having childhood ALL (95\% CI=0.97-2.70 and 0.54-3.43, $p=0.0627$ and 0.5048 , respectively). Even after adjustment for gender, the level was similar and did not reach the significance level (adjusted $\mathrm{OR}=1.78$ and $1.43,95 \% \mathrm{CI}=0.92-2.62$ and 0.52 - 
Table IV. Maternally expressed gene 3 (MEG3) rs11160608 genotypes among the 266 patients with childhood acute lymphoblastic leukemia and 266 healthy controls.

\begin{tabular}{|c|c|c|c|c|c|}
\hline & & Controls, n (\%) & Patients, n (\%) & OR $(95 \% \mathrm{CI})$ & $p$-Value ${ }^{a}$ \\
\hline \multirow[t]{5}{*}{ Genotype } & AA & $85(32.0 \%)$ & $80(30.1 \%)$ & 1.00 (Reference) & \\
\hline & $\mathrm{AC}$ & $131(49.2 \%)$ & $137(51.5 \%)$ & $1.11(0.75-1.64)$ & 0.5944 \\
\hline & $\mathrm{CC}$ & $50(18.8 \%)$ & $49(18.4 \%)$ & $1.04(0.63-1.71)$ & 0.8737 \\
\hline & $p_{\text {trend }}$ & & & & 0.8625 \\
\hline & $p_{\mathrm{HWE}}$ & & & & 0.9699 \\
\hline \multirow[t]{4}{*}{ Carrier comparison } & $\mathrm{AA}+\mathrm{AC}$ & $216(81.2 \%)$ & $217(81.6 \%)$ & 1.00 (Reference) & \\
\hline & $\mathrm{CC}$ & $50(18.8 \%)$ & $49(18.4 \%)$ & $0.98(0.63-1.51)$ & 0.9113 \\
\hline & $\mathrm{AA}$ & $85(32.0 \%)$ & $80(30.1 \%)$ & 1.00 (Reference) & \\
\hline & $\mathrm{AC}+\mathrm{CC}$ & $181(68.0 \%)$ & $186(69.9 \%)$ & $1.09(0.76-1.58)$ & 0.6393 \\
\hline
\end{tabular}

CI: Confidence interval; OR: odds ratio; ptrend: $p$-value for trend analysis; $p_{\mathrm{HWE}}$ : $p$-value for Hardy-Weinberg equilibrium analysis. aBased on chi-square test without Yates' correction.

Table V. Maternally expressed gene 3 (MEG3) rs4081134 genotypes among the 266 patients with childhood acute lymphoblastic leukemia and 266 healthy controls.

\begin{tabular}{llcrrr}
\hline & & Controls, $\mathrm{n}(\%)$ & Patients, $\mathrm{n}(\%)$ & OR (95\% CI) & $p$-Value ${ }^{\mathrm{a}}$ \\
\hline Genotype & GG & $149(56.0 \%)$ & $141(53.0 \%)$ & 1.00 (Reference) & 0.5345 \\
& AG & $101(38.0 \%)$ & $107(40.2 \%)$ & $1.12(0.78-1.60)$ & 0.6335 \\
& AA & $16(6.0 \%)$ & $18(6.8 \%)$ & & 0.7744 \\
& $p_{\text {trend }}$ & & & & 0.8381 \\
& $p_{\text {HWE }}$ & & & 1.00 (Reference) & $0.72 .42)$ \\
& GG+AG & $250(94.0 \%)$ & $248(93.2 \%)$ & $1.13(0.57-2.27)$ & 1.00 (Reference) \\
& AA & $16(6.0 \%)$ & $141(53.0 \%)$ & $1.13(0.80-1.59)$ & 0.4861 \\
\hline
\end{tabular}

CI: Confidence interval; OR: odds ratio; $p_{\text {trend }}$ p-value for trend analysis; pHWE: $p$-value for Hardy-Weinberg equilibrium analysis. ${ }^{\text {aBBased }}$ on chi-square test without Yates' correction.

Table VI. Distribution of allelic frequencies for rs 7158663 , rs3087918, rs 11160608 and rs4081134 single nucleotide polymorphisms (SNPs) of maternally expressed gene 3 (MEG3) among the 266 patients with childhood acute lymphoblastic leukemia and 266 healthy controls.

\begin{tabular}{|c|c|c|c|c|c|}
\hline SNP & Allele & Controls, n (\%) & Cases, n (\%) & OR $(95 \% \mathrm{CI})$ & $p$-Value ${ }^{a}$ \\
\hline \multirow[t]{2}{*}{ rs 7158663} & G & $402(75.6 \%)$ & $355(66.7 \%)$ & 1.00 (Reference) & \\
\hline & A & $130(24.4 \%)$ & $177(33.3 \%)$ & $1.54(1.18-2.01)$ & 0.0015 \\
\hline \multirow[t]{2}{*}{ rs3087918 } & $\mathrm{T}$ & $324(60.9 \%)$ & $339(63.7 \%)$ & 1.00 (Reference) & \\
\hline & G & $208(39.1 \%)$ & $193(36.3 \%)$ & $0.89(0.69-1.14)$ & 0.3427 \\
\hline \multirow[t]{2}{*}{ rs11160608 } & A & $301(56.6 \%)$ & $297(55.8 \%)$ & 1.00 (Reference) & \\
\hline & $\mathrm{C}$ & $231(43.4 \%)$ & $235(44.2 \%)$ & $1.03(0.81-1.31)$ & 0.8048 \\
\hline \multirow[t]{2}{*}{ rs 4081134} & G & $399(75.0 \%)$ & $389(73.1 \%)$ & 1.00 (Reference) & \\
\hline & A & $133(25.0 \%)$ & $143(26.9 \%)$ & $1.10(0.84-1.45)$ & 0.4843 \\
\hline
\end{tabular}

CI: Confidence interval; OR: odds ratio. ${ }^{\text {aB }}$ ased on chi-square test without Yates' correction. Statistically significant $p$-values are shown in bold.

3.34, respectively) (Table VII). Among children aged 3.5 years and over, those with MEG3 rs7158663 AA genotype were at 3.49-fold odds of having childhood ALL (95\% $\mathrm{CI}=1.36-8.92, p=0.0066)$. The difference was even more significant after adjusting for gender (adjusted $\mathrm{OR}=3.52$, 95\% CI=1.42-8.75, 0.0066; Table VII).

Table VIII shows that among boys, those with MEG3 rs7158663 AG and AA genotypes had 1.75- and 3.11-fold of 
Pei et al: MEG3 Genotype in Childhood Leukemia

Table VII. Maternally expressed gene 3 (MEG3) rs7158663 genotype in childhood acute lymphoblastic leukemia risk after stratification by age.

\begin{tabular}{|c|c|c|c|c|c|c|c|c|c|c|}
\hline \multirow[b]{2}{*}{ Genotype } & \multicolumn{5}{|c|}{ Age $<3.5$ years } & \multicolumn{5}{|c|}{ Age $\geq 3.5$ years, $n(\%)$} \\
\hline & $\begin{array}{c}\text { Controls, } \\
\text { n (\%) }\end{array}$ & $\begin{array}{c}\text { Cases, } \\
\mathrm{n}(\%)\end{array}$ & $\begin{array}{c}\text { OR } \\
(95 \% \mathrm{CI})^{\mathrm{a}}\end{array}$ & $\begin{array}{c}\mathrm{aOR} \\
(95 \% \mathrm{CI})^{\mathrm{b}}\end{array}$ & $p$-Value & $\begin{array}{c}\text { Controls, } \\
\mathrm{n}(\%)\end{array}$ & $\begin{array}{l}\text { Cases, } \\
\mathrm{n}(\%)\end{array}$ & $\begin{array}{c}\text { OR } \\
(95 \% \mathrm{CI})^{\mathrm{a}}\end{array}$ & $\begin{array}{c}\mathrm{aOR} \\
(95 \% \mathrm{CI})^{\mathrm{b}}\end{array}$ & $p$-Value \\
\hline GG & 77 (57.9) & $62(46.6)$ & 1.00 (ref) & 1.00 (ref) & & $76(57.1)$ & $56(42.1)$ & 1.00 (ref) & 1.00 (ref) & \\
\hline AG & $46(34.6)$ & $60(45.1)$ & $1.62(0.97-2.70)$ & $1.78(0.92-2.62)$ & 0.0627 & $50(37.6)$ & $59(44.4)$ & $1.60(0.96-2.67)$ & $1.65(0.93-2.72)$ & 0.0702 \\
\hline AA & $10(7.5)$ & $11(8.3)$ & $1.37(0.54-3.43)$ & $1.43(0.52-3.34)$ & 0.5048 & $7(5.3)$ & $18(13.5)$ & $3.49(1.36-8.92)$ & $3.52(1.42-8.75)$ & 0.0066 \\
\hline Total & 133 & 133 & & & & 133 & 133 & & & \\
\hline$p_{\text {trend }}$ & & & & & 0.1724 & & & & & 0.0135 \\
\hline
\end{tabular}

CI: Confidence interval; aOR, adjusted odds ratio; OR: odds ratio; $p_{\text {trend }}, p$-value for trend analysis. ${ }^{\text {aBy }}$ multivariate logistic regression analysis; by multivariate logistic regression analysis after adjusting for gender. Statistically significant $p$-values are shown in bold.

Table VIII. Maternally expressed gene 3 (MEG3) rs7158663 genotype in childhood acute lymphoblastic leukemia risk after stratification by gender.

\begin{tabular}{|c|c|c|c|c|c|c|c|c|c|c|}
\hline \multirow[b]{2}{*}{ Genotype } & \multicolumn{5}{|c|}{ Male } & \multicolumn{5}{|c|}{ Female } \\
\hline & $\begin{array}{c}\text { Controls, } \\
\text { n }(\%)\end{array}$ & $\begin{array}{l}\text { Cases, } \\
\mathrm{n}(\%)\end{array}$ & $\begin{array}{c}\text { OR } \\
(95 \% \mathrm{CI})^{\mathrm{a}}\end{array}$ & $\begin{array}{c}\mathrm{aOR} \\
(95 \% \mathrm{CI})^{\mathrm{b}}\end{array}$ & $p$-Value & $\begin{array}{c}\text { Controls, } \\
\text { n }(\%)\end{array}$ & $\begin{array}{l}\text { Cases, } \\
\mathrm{n}(\%)\end{array}$ & $\begin{array}{c}\text { OR } \\
(95 \% \mathrm{CI})^{\mathrm{a}}\end{array}$ & $\begin{array}{c}\mathrm{aOR} \\
(95 \% \mathrm{CI})^{\mathrm{b}}\end{array}$ & $p$-Value \\
\hline GG & $87(58.8)$ & $63(42.6)$ & 1.00 (ref) & 1.00 (ref) & & $66(55.9)$ & 55 (46.6) & 1.00 (ref) & 1.00 (ref) & \\
\hline $\mathrm{AG}$ & $53(35.8)$ & $67(45.3)$ & $1.75(1.08-2.83)$ & $1.63(1.02-2.07)$ & 0.0238 & $43(36.4)$ & $52(44.1)$ & $1.45(0.85-2.49)$ & $1.37(0.73-2.06)$ & 0.1756 \\
\hline AA & $8(5.4)$ & $18(12.1)$ & $3.11(1.27-7.59)$ & $2.59(1.34-4.49)$ & 0.0101 & $9(7.7)$ & $11(9.3)$ & $1.47(0.57-3.80)$ & $1.41(0.49-2.77)$ & 0.4281 \\
\hline Total & 148 & 148 & & & & 118 & 118 & & & \\
\hline$p_{\text {trend }}$ & & & & & 0.0095 & & & & & 0.3583 \\
\hline
\end{tabular}

CI: Confidence interval; aOR, adjusted odds ratio; OR: odds ratio; $p_{\text {trend }}, p$-value for trend analysis. ${ }^{\text {B }}$ y multivariate logistic regression analysis; by multivariate logistic regression analysis after adjusting for age. Statistically significant $p$-values are shown in bold.

odds of having childhood ALL (95\% CI=1.08-2.83 and 1.277.59, $p=0.0238$ and 0.0101$)$, respectively. Even after adjustment for age, the significance remained (adjusted $\mathrm{OR}=1.63$ and $2.59,95 \% \mathrm{CI}=1.02-2.07$ and $1.34-4.49$, respectively) (Table VIII). Among girls, these differences were not as obvious as for the boys, no matter their genotype, nor before and after adjusting for their age (Table VIII).

\section{Discussion}

lncRNAs play a critical role in leukemia development and scientists are devoted to elucidating their various biological functions involved in leukemia carcinogenesis (15). Among these, MEG3 is a tumor suppressor, and via various signaling pathways, it is highly involved in the regulation of the p53 expression and p53-dependent transcription (23). In a panel of cancer types, protein expression of lncRNA MEG3 was found to be down-regulated in gastric, liver, colorectal, breast and ovarian cancer (24). However, (childhood) leukemia is not in this list. SNPs of MEG3 have been associated with cell phenotype alteration, cancer susceptibility, and chemotherapy toxicity in patients with solid tumors $(24,25)$. To our knowledge, the current study is the first to investigate the association of MEG3 genotypes with childhood leukemia.

In the current study, we revealed that the frequencies of $\mathrm{GG}, \mathrm{AG}$, and AA genotypes at MEG3 rs7158663 were $57.5 \%, 36.1 \%$, and $6.4 \%$ in healthy Taiwanese controls (Table II). Among the childhood ALL cases, MEG3 rs7158663 variants AG and AA were both statistically significantly more frequent $(44.7 \%$ and $10.9 \%)$ than in the corresponding controls (Table II). We confirmed the findings via carrier comparisons and allelic frequency analysis, revealing that variant AA genotype and $\mathrm{A}$ allele contribute to elevated childhood ALL risk (Table II and Table VI). On the contrary, no positive association was found for MEG3 rs3087918, rs11160608, or rs4081134 (Table III, Table IV, Table V and Table VI). In addition, the present study is the first to reveal a significant interaction of MEG3 rs7158663 genotypes with age and gender for childhood ALL risk (Table VII and Table VIII). Our studies demonstrated that older children ( $\geq 3.5$ years old) with AA genotype at MEG3 rs7158663 and boys carrying one or more A alleles tended to be more likely to have childhood ALL (Table VII and Table VIII). The detailed mechanisms of how MEG3 
Table IX. Summary of findings from literature (until 31/10/2021) on the association of single nucleotide polymorphisms of maternally expressed gene 3 (MEG3) genotype among different types of cancer.

\begin{tabular}{|c|c|c|c|c|c|c|}
\hline $\begin{array}{l}\text { First author } \\
\text { (Ref) }\end{array}$ & $\begin{array}{c}\text { Year } \\
\text { published }\end{array}$ & $\begin{array}{l}\text { Cohort } \\
\text { ethnicity }\end{array}$ & $\begin{array}{c}\text { Cancer } \\
\text { type }\end{array}$ & $\begin{array}{c}\text { Controls, } \\
\mathrm{n}\end{array}$ & $\begin{array}{c}\text { Cases, } \\
\mathrm{n}\end{array}$ & Highlight of genotyping findings \\
\hline Cao et al. (26) & 2016 & Han & Colorectal & 527 & 518 & $\begin{array}{l}\text { rs } 7158663 \text { AA genotype contributed to higher risk } \\
\text { rs3087918 did not contribute to altered risk } \\
\text { rs11160608 did not contribute to altered risk } \\
\text { rs4081134 did not contribute to altered risk } \\
\text { rs10144253 did not contribute to altered risk }\end{array}$ \\
\hline Yang et al. (27) & 2018 & Han & Lung & 526 & 526 & $\begin{array}{l}\text { rs4081134 AA genotype contributed to lower risk } \\
\text { rs7158663 did not contribute to altered risk }\end{array}$ \\
\hline Zhuo et al. (28) & 2018 & Han & Neuroblastoma & 783 & 392 & $\begin{array}{l}\text { rs } 4081134 \mathrm{AA} / \mathrm{AG} \text { genotypes contributed to higher risk } \\
\text { rs } 7158663 \text { did not contribute to altered risk }\end{array}$ \\
\hline Hou et al. (29) & 2019 & Han & Oral & 984 & 444 & $\begin{array}{l}\text { rs11160608 AC genotype contributed to higher risk } \\
\text { rs } 3783355 \text { did not contribute to altered risk } \\
\text { rs } 4378559 \text { did not contribute to altered risk } \\
\text { rs4906024 did not contribute to altered risk } \\
\text { rs } 4081134 \text { did not contribute to altered risk } \\
\text { rs2281511 did not contribute to altered risk } \\
\text { rs12431658 did not contribute to altered risk }\end{array}$ \\
\hline Ali et al. (24) & 2020 & Egyptian & Breast & 154 & 150 & rs7158663 AA genotype contributed to higher risk \\
\hline Zheng et al. (25) & 2020 & Han & Breast & 700 & 434 & $\begin{array}{l}\text { rs3087918 GG genotype contributed to lower risk } \\
\text { rs7158663 did not contribute to altered risk } \\
\text { rs3087918 did not contribute to altered risk }\end{array}$ \\
\hline $\mathrm{Xu}$ et al. (30) & 2021 & Han & Prostate & 200 & 165 & $\begin{array}{l}\text { rs11627993 did not contribute to altered risk } \\
\text { rs7158663 did not contribute to altered risk }\end{array}$ \\
\hline Shaker et al. (31) & 2021 & Egyptian & Breast & 150 & 180 & rs7158663 AG/AA genotypes contributed to higher risk \\
\hline Pei et al. & Current & Taiwanese & Childhood ALL & 266 & 266 & $\begin{array}{l}\text { rs7158663 AG/AA genotypes contributed to higher risk } \\
\text { rs3087918 did not contribute to altered risk } \\
\text { rs11160608 did not contribute to altered risk } \\
\text { rs4081134 did not contribute to altered risk }\end{array}$ \\
\hline
\end{tabular}

ALL: Acute lymphocytic leukemia.

genotype contributes to age and gender differences in the etiology of childhood ALL need further investigation.

In literature, there are very few articles reporting the association of MEG3 genotypes with cancer risk, not to mention (childhood) leukemia. This does not mean the MEG3 genotype is irrelevant to cancer development, on the contrary, it means that genotyping investigations focusing on $M E G 3$ genotypes and their contribution to all types of cancer are urgently needed. To provide a clearer picture of how important MEG3 genotypes are in determining and predicting cancer risk, we summarize the contribution of $M E G 3$ genotypes to cancer risk as given in literature.

In 2016, Cao et al. explored the contributions of five MEG3 polymorphic variants, rs3087918, rs11160608, rs7158663, rs4081134 and rs10144253, to colorectal cancer risk. They found that only the AA genotype of MEG3 rs7158663 significantly increased colorectal cancer risk, especially in those aged less than 60 years and with a family history of cancer (26). In 2018, Yang et aI. examined the associations of $M E G 3$ rs7158663 and rs4081134 with lung cancer risk with a 526-case and 526-control Han population. They found that the
AA genotype of MEG3 rs4081134 may be associated with a reduced lung cancer risk, while no association between the MEG3 rs7158663 genotype and lung cancer risk was found (27). In the same year, Zhuo and colleagues explored the role of MEG3 rs7158663 and rs4081134 in childhood neuroblastoma. Theirs was a very valuable in case-control study since the research in childhood neuroblastoma are quite rare, and the sample size was relatively large, with 392 cases and 783 controls. They found AG and AA genotypes of MEG3 rs4081134 tended to develop neuroblastoma among subgroups aged $>18$ months and with clinical stage III/IV disease. No association of MEG3 rs7158663 with childhood neuroblastoma was found (28). In 2019, Hou and colleagues investigated the contributions of the genotypes of seven polymorphic sites on MEG3, rs4378559, rs3783355, rs11160608, rs4906024, rs4081134, rs2281511 and rs12431658, to oral cancer risk. The polymorphic sites are all intronic sites, while they omitted MEG3 rs7158663. They found a critical role of MEG3 rs11160608 in oral carcinogenesis within a Han population of 984 controls and 444 cases. They also conducted a phenotypic luciferase assay, reporting that the activity of $M E G 3$ 
rs11160608 A allele was lower than that of the rs11160608 C allele (29). In 2020, Ali et al. attempted to determine the influence of MEG3 rs7158663 on the serum MEG3 level and breast cancer risk in an Egyptian population of 154 controls and 150 patients with breast cancer. They found the AA genotype at MEG3 rs7158663 not only correlated with a lower level expression of $M E G 3$ in serum, but also with an elevated breast cancer risk (24). In 2020, Zheng and colleagues examined the contribution of MEG3 rs3087918, rs7158663 and rs11160608 to breast cancer risk with 434 cases and 700 controls. They found the GG genotype of MEG3 rs3087918 was associated with a reduced risk of breast cancer (25). In 2021, Xu et al. explored the association of MEG3 rs11627993 and rs7158663 with prostate cancer risk in a Han population of 165 cases and 200 controls. They had no positive finding (30). Recently, Shaker and colleagues investigated the impact of genotypes of MEG3 rs7158663 on the expression levels of microRNA-182 and microRNA-29, and on breast cancer risk in a moderate Egyptian population of 150 controls, 120 fibroadenoma and 180 breast cancer cases. The AG and AA genotypes contributed to a higher risk of breast cancer. Moreover, the A allele of MEG3 rs7158663 was associated with a significantly lower serum level of $M E G 3$, which correlated with higher TMN staging and larger tumor size among the breast cancer cases (31) (Table IX).

Several limitations and potential improvements of the present study should be noted. Firstly, these findings were based on genomic analysis of a single gene with a relatively moderate sample size of childhood ALL cases which need to be validated using more independent and larger investigations. Secondly, our study was a hospital-based study, although two well-known and outstanding medical centers were involved. Therefore, potential sources of selection bias may exist. Thirdly, the current study had incomplete information on lifestyle, environmental and familial factors which may contribute to childhood ALL. Further studies are needed to reveal the correlation of lifestyle/environmental information and family history with genetic variants such as MEG3 in childhood ALL. The mRNA level of MEG3 was reported to be lower in patients with breast cancer than in healthy controls, and those with MEG3 rs7158663 AA genotype had the lowest level among the various genotypes (24). Therefore, the phenotype of MEG3 rs7158663 AA genotype should be validated among patients with childhood ALL, and the consequences of a lower serum MEG3 level should be further investigated.

In conclusion, this study provides first-hand evidence that the A allele at MEG3 rs7158663 may serve as a predictor for childhood ALL. Moreover, there was an obvious interaction of age ( $\geq 3.5$ years) and gender (boys) with MEG3 rs7158663 genotype on personal susceptibility to childhood ALL. Further studies are needed to validate the clinical practicability of this novel biomarker.

\section{Conflicts of Interest}

All the Authors declare no conflicts of interest in this study.

\section{Authors' Contributions}

Research Design: Pei JS, Chang WS, Bau DT and Tsai CW; Patient and Questionnaire Summarize: Chen CC, Pei JS and Hsu PC; Experiment Data Clearing and Checking: Mong MC and Hsu SW; Statistical Analysis: Hsu YN and Wang YC Manuscript Writing: Chang WS, Tsai CW and Bau DT; Reviewing and Revising: Bau DT.

\section{Acknowledgements}

The expert DNA extraction technology and statistical analysis from Yu-Chen Hsiau, Tzu-Yu Wang and Tzu-Hsuan Wang are appreciated. This study was supported by the grant from Taoyuan General Hospital, Ministry of Health and Welfare (PTH109032) and China Medical University Hospital and Asia University (CMU110-ASIA-05).

\section{References}

1 Eden T: Aetiology of childhood leukaemia. Cancer Treat Rev 36(4): 286-297, 2010. PMID: 20223594. DOI: 10.1016/j.ctrv.2010.02.004

2 Terracini B: Epidemiology of childhood cancer. Environ Health 10(Suppl 1): S8, 2011. PMID: 21489218. DOI: 10.1186/1476069X-10-S1-S8

3 Karathanasis NV, Choumerianou DM and Kalmanti M: Gene polymorphisms in childhood ALL. Pediatr Blood Cancer 52(3): 318-323, 2009. PMID: 18989891. DOI: 10.1002/pbc.21825

4 Bhojwani D, Yang JJ and Pui CH: Biology of childhood acute lymphoblastic leukemia. Pediatr Clin North Am 62(1): 47-60, 2015. PMID: 25435111. DOI: 10.1016/j.pcl.2014.09.004

5 Schüz J and Erdmann F: Environmental exposure and risk of childhood leukemia: an overview. Arch Med Res 47(8): 607-614, 2016. PMID: 28476188. DOI: 10.1016/j.arcmed.2016.11.017

6 Hsu PC, Pei JS, Chen CC, Chang WS, Chin YT, Huang TL, Yang JS, Wang YC, Chen JC, Hsu YN, Tsai CW and Bau DT: Significant association of $C C N D 1$ genotypes with susceptibility to childhood acute lymphoblastic leukemia. Anticancer Res 41(10): 4801-4806, 2021. PMID: 34593429. DOI: 10.21873/anticanres.15295

7 Pei JS, Chen CC, Chang WS, Wang YC, Chen JC, Hsiau YC, Hsu PC, Hsu YN, Tsai CW and Bau DT: Significant associations of lncRNA H19 genotypes with susceptibility to childhood leukemia in Taiwan. Pharmaceuticals (Basel) 14(3): 235, 2021. PMID: 33800276. DOI: 10.3390/ph14030235

8 Chen CC, Hsu PC, Shih LC, Hsu YN, Kuo CC, Chao CY, Chang WS, Tsai CW, Bau DT and Pei JS: MiR-196a-2 genotypes determine the susceptibility and early onset of childhood acute lymphoblastic leukemia. Anticancer Res 40(8): 4465-4469, 2020. PMID: 32727776. DOI: 10.21873/anticanres.14451

9 Pei JS, Chang WS, Hsu PC, Chen CC, Chin YT, Huang TL, Hsu YN, Kuo CC, Wang YC, Tsai CW, Gong CL and Bau DT: Significant association between the MiR146a genotypes and susceptibility to childhood acute lymphoblastic leukemia in Taiwan. Cancer Genomics Proteomics 17(2): 175-180, 2020. PMID: 32108040. DOI: $10.21873 / \operatorname{cgp} .20178$ 
10 Pei JS, Chang WS, Hsu PC, Chen CC, Cheng SP, Wang YC, Tsai $\mathrm{CW}$, Shen TC and Bau DT: The contribution of XRCC3 genotypes to childhood acute lymphoblastic leukemia. Cancer Manag Res 10: 5677-5684, 2018. PMID: 30532590. DOI: 10.2147/CMAR.S178411

11 Pei JS, Chou AK, Hsu PC, Tsai CW, Chang WS, Wu MF, Wu $\mathrm{MH}$, Hsia TC, Cheng SP and Bau DT: Contribution of matrix metalloproteinase-7 genotypes to the risk of non-solid tumor, childhood leukemia. Anticancer Res 37(12): 6679-6684, 2017. PMID: 29187444. DOI: 10.21873 /anticanres.12126

12 Ørom UA and Shiekhattar R: Long noncoding RNAs usher in a new era in the biology of enhancers. Cell 154(6): 1190-1193, 2013. PMID: 24034243. DOI: 10.1016/j.cell.2013.08.028

13 Geisler S and Coller J: RNA in unexpected places: long noncoding RNA functions in diverse cellular contexts. Nat Rev Mol Cell Biol 14(11): 699-712, 2013. PMID: 24105322. DOI: $10.1038 / \mathrm{nrm} 3679$

14 Guttman M, Donaghey J, Carey BW, Garber M, Grenier JK, Munson G, Young G, Lucas AB, Ach R, Bruhn L, Yang X, Amit I, Meissner A, Regev A, Rinn JL, Root DE and Lander ES: lincRNAs act in the circuitry controlling pluripotency and differentiation. Nature 477(7364): 295-300, 2011. PMID: 21874018. DOI: $10.1038 /$ nature 10398

15 Bhat AA, Younes SN, Raza SS, Zarif L, Nisar S, Ahmed I, Mir R, Kumar S, Sharawat SK, Hashem S, Elfaki I, Kulinski M, Kuttikrishnan S, Prabhu KS, Khan AQ, Yadav SK, El-Rifai W, Zargar MA, Zayed H, Haris M and Uddin S: Role of non-coding RNA networks in leukemia progression, metastasis and drug resistance. Mol Cancer 19(1): 57, 2020. PMID: 32164715. DOI: 10.1186/s12943-020-01175-9

16 Balik V, Srovnal J, Sulla I, Kalita O, Foltanova T, Vaverka M, Hrabalek L and Hajduch M: MEG3: a novel long noncoding potentially tumour-suppressing RNA in meningiomas. J Neurooncol 112(1): 1-8, 2013. PMID: 23307326. DOI: 10.1007/s11060-012$1038-6$

17 Bayarmaa B, Wu Z, Peng J, Wang Y, Xu S, Yan T, Yin W, Lu J and Zhou L: Association of LncRNA MEG3 polymorphisms with efficacy of neoadjuvant chemotherapy in breast cancer. BMC Cancer 19(1): 877, 2019. PMID: 31488093. DOI: 10.1186/s12885-019-6077-3

18 Ying L, Huang Y, Chen H, Wang Y, Xia L, Chen Y, Liu Y and Qiu F: Downregulated MEG3 activates autophagy and increases cell proliferation in bladder cancer. Mol Biosyst 9(3): 407-411, 2013. PMID: 23295831. DOI: 10.1039/c2mb25386k

19 Yan J, Guo X, Xia J, Shan T, Gu C, Liang Z, Zhao W and Jin $\mathrm{S}$ : MiR-148a regulates MEG3 in gastric cancer by targeting DNA methyltransferase 1. Med Oncol 31(3): 879, 2014. PMID: 24515776. DOI: 10.1007/s12032-014-0879-6

20 Terashima M, Tange S, Ishimura A and Suzuki T: MEG3 long noncoding RNA contributes to the epigenetic regulation of epithelial-mesenchymal transition in lung cancer cell lines. J Biol Chem 292(1): 82-99, 2017. PMID: 27852821. DOI: 10.1074/jbc.M116.750950

21 Braconi C, Kogure T, Valeri N, Huang N, Nuovo G, Costinean S, Negrini M, Miotto E, Croce CM and Patel T: microRNA-29 can regulate expression of the long non-coding RNA gene MEG3 in hepatocellular cancer. Oncogene 30(47): 4750-4756, 2011. PMID: 21625215. DOI: 10.1038/onc.2011.193
22 Yang MD, Lin KC, Lu MC, Jeng LB, Hsiao CL, Yueh TC, Fu CK, Li HT, Yen ST, Lin CW, Wu CW, Pang SY, Bau DT and Tsai FJ: Contribution of matrix metalloproteinases-1 genotypes to gastric cancer susceptibility in Taiwan. Biomedicine (Taipei) 7(2): 10, 2017. PMID: 28612708. DOI: 10.1051/bmden/2017070203

23 Ghafouri-Fard S and Taheri M: Maternally expressed gene 3 (MEG3): A tumor suppressor long non coding RNA. Biomed Pharmacother 118: 109129, 2019. PMID: 31326791. DOI: 10.1016/j.biopha.2019.109129

24 Ali MA, Shaker OG, Alazrak M, AbdelHafez MN, Khalefa AA, Hemeda NF, Abdelmoktader A and Ahmed FA: Association analyses of a genetic variant in long non-coding RNA MEG3 with breast cancer susceptibility and serum MEG3 expression level in the Egyptian population. Cancer Biomark 28(1): 49-63, 2020. PMID: 32176630. DOI: 10.3233/CBM-191072

25 Zheng Y, Wang M, Wang S, Xu P, Deng Y, Lin S, Li N, Liu K, Zhu Y, Zhai Z, Wu Y, Dai Z and Zhu G: LncRNA MEG3 rs3087918 was associated with a decreased breast cancer risk in a Chinese population: a case-control study. BMC Cancer 20(1): 659, 2020. PMID: 32669097. DOI: 10.1186/s 12885-020-07145-0

26 Cao X, Zhuang S, Hu Y, Xi L, Deng L, Sheng H and Shen W: Associations between polymorphisms of long non-coding RNA MEG3 and risk of colorectal cancer in Chinese. Oncotarget 7(14): 19054-19059, 2016. PMID: 26934323. DOI: 10.18632/ oncotarget.7764

27 Yang Z, Li H, Li J, Lv X, Gao M, Bi Y, Zhang Z, Wang S, Li S, Li N, Cui Z, Zhou B and Yin Z: Association between long noncoding RNA MEG3 polymorphisms and lung cancer susceptibility in Chinese northeast population. DNA Cell Biol 37(10): 812-820, 2018. PMID: 30113224. DOI: 10.1089/dna.2018.4277

28 Zhuo ZJ, Zhang R, Zhang J, Zhu J, Yang T, Zou Y, He J and Xia $\mathrm{H}$ : Associations between lncRNA MEG3 polymorphisms and neuroblastoma risk in Chinese children. Aging (Albany NY) 10(3): 481-491, 2018. PMID: 29615542. DOI: 10.18632/aging.101406

29 Hou Y, Zhang B, Miao L, Ji Y, Yu Y, Zhu L, Ma H and Yuan H: Association of long non-coding RNA MEG3 polymorphisms with oral squamous cell carcinoma risk. Oral Dis 25(5): 13181324, 2019. PMID: 30947387. DOI: 10.1111/odi.13103

30 Xu B, Zhang M, Liu C, Wang C, You Z, Wang Y and Chen M: Association of long non-coding RNA MEG3 polymorphisms and risk of prostate cancer in Chinese Han population. Urol J 18(2): 176-180, 2020. PMID: 32827147. DOI: 10.22037/uj.v16i7.5585

31 Shaker O, Ayeldeen G and Abdelhamid A: The impact of single nucleotide polymorphism in the long non-coding MEG3 gene on MicroRNA-182 and MicroRNA-29 expression levels in the development of breast cancer in Egyptian women. Front Genet 12: 683809, 2021. PMID: 34421993. DOI: 10.3389/fgene.2021.683809

Received November 3, 2021

Revised December 1, 2021

Accepted December 3, 2021 